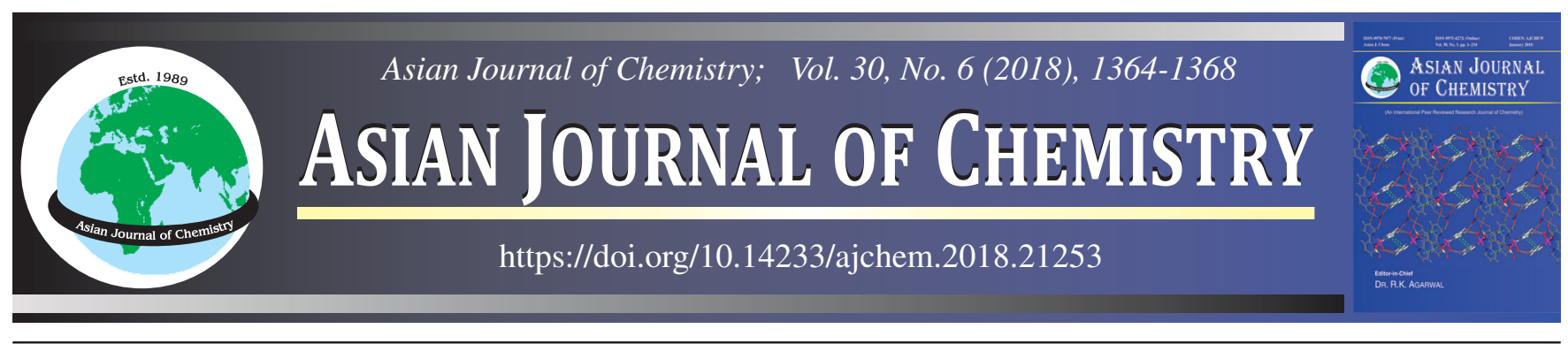

\title{
Synthesis and Characterization of Novel Diorganotin(IV) Complexes Derived from N-Methyl-phenethyl Dithiocarbamate and Bis(2-ethoxyethyl) Dithiocarbamate
}

Norraphat Uttraphan Pim ${ }^{1}$, Normah Awang ${ }^{2}$, Rapidah Mohamad ${ }^{1}$, Yang Farina Abdul Aziz ${ }^{3}$ and Nurul Farahana Kamaludin ${ }^{2, *}$

${ }^{1}$ Biomedical Science Programme, Faculty of Health Sciences, Universiti Kebangsaan Malaysia, Jalan Raja Muda Abdul Aziz, 50300 Kuala Lumpur, Malaysia

${ }^{2}$ Environmental Health and Industrial Safety Programme, Faculty of Health Sciences, Universiti Kebangsaan Malaysia, Jalan Raja Muda Abdul Aziz, 50300 Kuala Lumpur, Malaysia

${ }^{3}$ School of Chemical Sciences and Food Technology, Faculty of Science \& Technology, Universiti Kebangsaan Malaysia, 43600 Bangi, Selangor Darul Ehsan, Malaysia

*Corresponding author: E-mail: nurulfarahana@ukm.edu.my; norraphat_uttraphan@yahoo.com

Received: 27 January 2018;

Accepted: 24 February 2018;

Published online: 30 April 2018;

AJC-18895

Organotin(IV) dithiocarbamate complexes are extensively studied worldwide as they have proven to exhibit promising anticancer, antimicrobial and larvicidal properties. In this study, three new organotin(IV) dithiocarbamate complexes have been successfully synthesized via in situ reaction between the appropriate secondary amines with carbon disulphide and organotin(IV) salts, in a basic solution at temperature below $4{ }^{\circ} \mathrm{C}$. The complexes were characterized by CHNS elemental analysis, FTIR and ${ }^{1} \mathrm{H},{ }^{13} \mathrm{C}$ and ${ }^{119} \mathrm{Sn} \mathrm{NMR}$. All complexes displayed the important $\mathrm{NCS}_{2}$ peak from $200.02-201.35 \mathrm{ppm}$ in ${ }^{13} \mathrm{C} \mathrm{NMR}$, signifying the presence of the dithiocarbamate ligand. The complexes also produced the essential IR bands, $v(\mathrm{C}-\mathrm{N}), v(\mathrm{C}-\mathrm{S})$ and $v(\mathrm{Sn}-\mathrm{C})$ in the ranges 1489 to $1479 \mathrm{~cm}^{-1}, 986.2$ to $971.2 \mathrm{~cm}^{-1}$ and 568.2 to $550.8 \mathrm{~cm}^{-1}$, respectively. From the ${ }^{119} \mathrm{Sn}$ NMR, both the ligands were suggested to coordinate to the tin atom in a bidentate manner in all three complexes.

Keywords: Organotin(IV), Dithiocarbamate, Anticancer, Nanoparticles.

\section{INTRODUCTION}

Organotin compounds have at least one covalent carbontin bond $[1,2]$. This bond plays one of the major roles in the activity of the whole compound [3]. Organotin derivatives have gotten a lot of attention in the previous decades due to its numerous biological activities ranging from antibacterial and antifungal properties [4-8] to antiproliferative and anticancer properties [9-14] as well as larvicidal properties [15]. Most organotin(IV) compounds are found to be very toxic, even at low concentrations [1]. Their ability to induce various biological activities in different organisms and in small concentrations makes them the suitable candidates to be developed into future drugs.

One of the most popular organotin compounds are organotin(IV) dithiocarbamate compounds, which exhibited various biological activities as reported bynumerous previous studies. Organotin dithiocarbamate compounds are also good precursors for tin sulfide nanoparticles [16]. Dithiocarbamates are the analogs of carbamates, whereby both oxygen atoms of the carbamates are replaced by sulphur atoms. The dithiocar- bamate's possession of two donor sulphur atoms enables it to exhibit strong metal binding properties as they readily form chelates strongly and selectively with all transition metal ions [17], as well as with most main group metal ions [3]. In this particular ligand, coordination to the tin atom can occur in three different ways, i.e., monodentate, bidentate and an isobidentate [18], with bidenticity being the most common form of chelation [19]. Another interesting characteristic of the dithiocarbamate ligand is its ability to stabilize metal compounds with high oxidation number [19]. On the other hand, organotin(IV) cation has an ability to form complexes freely with ligands possessing $\mathrm{S}$, $\mathrm{N}, \mathrm{O}$ and $\mathrm{P}$ donor atoms [1]. This makes dithiocarbamate a good ligand for complexation with tin ions.

In an organotin compound, the organotin moiety exerts the cytotoxicity [20]. It is the nature and the number of alkyl groups bonded to the tin atom that give organotin compounds varying degrees of toxicity [1,21]. Meanwhile, the ligand plays an important role in transporting the molecules to the target while preventing premature interactions with biomolecules. For this purpose, sulfur-containing ligands are particularly suitable to carry out the task [20]. 
In this study, three new diorganotin(IV) complexes derived from $N$-methyl-phenethyl and bis(2-ethoxyethyl) dithiocarbamate ligands were successfully synthesized via in situ method of synthesis as decribed by Ivin and Lillie [22], with modifications. The new complexes were characterized by CHNS elemental analysis, FTIR and ${ }^{1} \mathrm{H},{ }^{13} \mathrm{C}$ and ${ }^{119} \mathrm{Sn}$ NMR to further clarify their structures.

\section{EXPERIMENTAL}

All chemicals and solvents were purchased and used as received without further purification from the suppliers. The chemicals and solvents were purchased from: $N$-methyl-phenethylamine (Sigma-Aldrich, USA), bis(2-ethoxyethyl)amine (TCI Chemicals, Japan), denatured ethanol (HmbG Chemicals, Germany), $25 \%$ ammonia solution (Merck, Germany), carbon disulphide (Merck, Germany), $97 \%$ dimethyltin(IV) dichloride (Sigma-Aldrich, USA) and $96 \%$ dibutyltin(IV) dichloride (Sigma-Aldrich, USA).

The percentage of carbon, hydrogen, nitrogen and sulphur were determined using an elemental analyzer (CHNS-O), model LECO 932. FTIR spectra were recorded in the range 4000-400 $\mathrm{cm}^{-1}$ using a Perkin-Elmer GX spectrophotometer on $\mathrm{KBr}$ disc. The ${ }^{1} \mathrm{H},{ }^{13} \mathrm{C}$ and ${ }^{119} \mathrm{Sn}$ nuclear magnetic resonance spectra were recorded in deuterated chloroform using Bruker Avance 400 III HD. The melting points were determined in open capillary tubes using an automated melting point apparatus, MPA120 EZ-Melt. All the analyses were conducted in Universiti Kebangsaan Malaysia, Bangi, Malaysia.

Synthesis of dimethyltin(IV) $N$-methyl-phenethyl dithiocarbamate (complex 1) and dibutyltin(IV) $N$-methylphenethyl dithiocarbamate (complex 2): Initially, $N$-methylphenethylamine $(0.01 \mathrm{~mol}, 1.5 \mathrm{~mL})$ was stirred with denatured ethanol $(10 \mathrm{~mL})$ and $25 \%$ ammonia solution $(3 \mathrm{~mL})$ in an ice bath for 15 min to maintain the temperature at $<4{ }^{\circ} \mathrm{C}$. A cold ethanolic solution of $\mathrm{CS}_{2}(0.01 \mathrm{~mol}, 0.6 \mathrm{~mL})$ was then added into the solution drop-wise and the solution was left to stir for 3 to $6 \mathrm{~h}$ for ligand formation. A faint yellowish solution was observed immediately upon addition of $\mathrm{CS}_{2}$ to the amine mixture. Next, organotin salt (0.005 mol-1.1 g dimethyltin, $1.5 \mathrm{~g}$ dibutyltin) was dissolved completely in cold ethanol and the solution was added to the dithiocarbamate ligand mixture drop-wise. The mixture was stirred for another $2 \mathrm{~h}$ until thick white precipitate was obtained. The white precipitate was then filtered and washed adequately with cold ethanol and dried in a desiccator overnight. Both complexes were synthesized according to the stoichiometric ratios of 2:2:1 for amine: $\mathrm{CS}_{2}$ : organotin salt. The synthesis of complexes $\mathbf{1}$ and $\mathbf{2}$ is illustrated in Scheme-I.

Synthesis of dibutyltin(IV) bis(2-ethoxyethyl) dithiocarbamate (complex 3): In an ice bath, $25 \%$ ammonia solution $(8 \mathrm{~mL})$ was stirred with denatured ethanol $(10 \mathrm{~mL})$ for a few minutes to attain temperature of $<4^{\circ} \mathrm{C}$. To the stirring mixture, bis(2-ethoxyethyl)amine $(0.01 \mathrm{~mol}, 1.8 \mathrm{~mL})$ was added dropwise. After $30 \mathrm{~min}$, a cold ethanolic solution of $\mathrm{CS}_{2}(0.01 \mathrm{~mol}$, $0.6 \mathrm{~mL}$ ) was slowly drop-wise added and the solution was left to stir at $<4{ }^{\circ} \mathrm{C}$ for $3 \mathrm{~h}$. A faint yellowish solution was observed immediately upon addition of $\mathrm{CS}_{2}$ to the amine mixture. Next, organotin salt $(0.005 \mathrm{~mol}, 1.5 \mathrm{~g})$ was dissolved completely in cold ethanol and dropwise added to the ligand. The mixture was left to stir for another $3 \mathrm{~h}$ until minimal white precipitate was observed. After removing the magnetic stirrer, the beaker was covered with parafilm and left in the fridge without disturbance for 3 days. Crystalline solids were obtained in the mixture after 3 days and then dried in a desiccator overnight. The complex was synthesized according to the stoichiometric ratios of 2:2:1 for amine: $\mathrm{CS}_{2}$ :organotin salt. The synthesis of complex $\mathbf{3}$ is illustrated in Scheme-II.

\section{RESULTS AND DISCUSSION}

Synthesis: The dithiocarbamate ligands were successfully synthesized via in situ method in equimolar amounts between the secondary amines ( $\mathrm{N}$-methyl-phenethyl amine and bis(2ethoxyethyl) amine and $\mathrm{CS}_{2}$ in a basic condition at $<4^{\circ} \mathrm{C}$. The complexes were successfully prepared from the reaction between respective organotin(IV) salts dissolved in cold ethanol with the freshly prepared ligands in a stoichiometric ratio. Complexation occurs when the chloride ions in the organotin(IV) salts were displaced by the respective ligands [3].

Complexes $\mathbf{1}$ and $\mathbf{2}$ were produced with fairly high yield (>50\%), which indicates that the in situ method is a suitable method of synthesis [7]. Both complexes are stable at room temperature and are in white powder form. Complex $\mathbf{3}$, which is in crystalline solid form, is fairly stable at room temperature albeit having a relatively low melting point compared to the<smiles></smiles>

Scheme-I: Reaction mechanism of complex $\mathbf{1}\left(\mathrm{R}=\mathrm{CH}_{3}\right)$ and complex $2\left(\mathrm{R}=\mathrm{C}_{4} \mathrm{H}_{9}\right)$

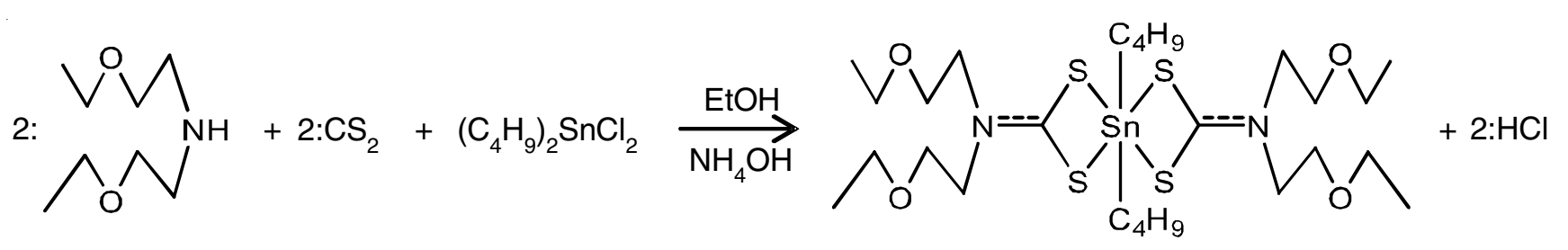

Scheme-II: Reaction mechanism of complex $3\left(\mathrm{R}=\mathrm{C}_{4} \mathrm{H}_{9}\right)$ 
other two complexes. However, complex $\mathbf{3}$ is stored at low temperature to maintain its structure and stability. All the complexes exhibited narrow melting point ranges $\left(<3{ }^{\circ} \mathrm{C}\right)$, showing that they are pure [7]. All the complexes are soluble in chloroform and dichloromethane. Figs. 1-3 illustrate the proposed structures of complexes $\mathbf{1}, \mathbf{2}$ and $\mathbf{3}$, respectively.

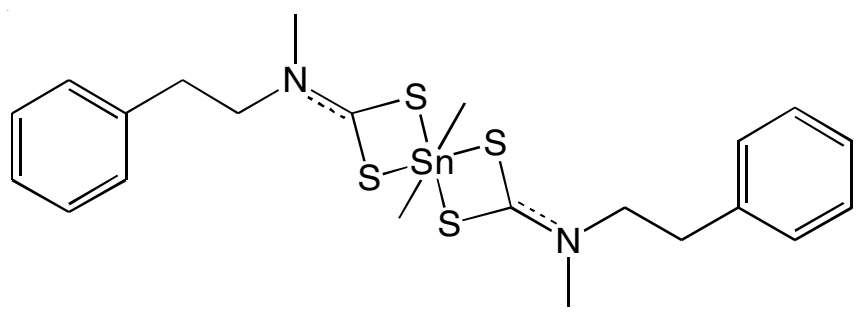

Fig. 1. Structure of dimethyltin(IV) $N$-methyl-phenethyl dithiocarbamate (1)

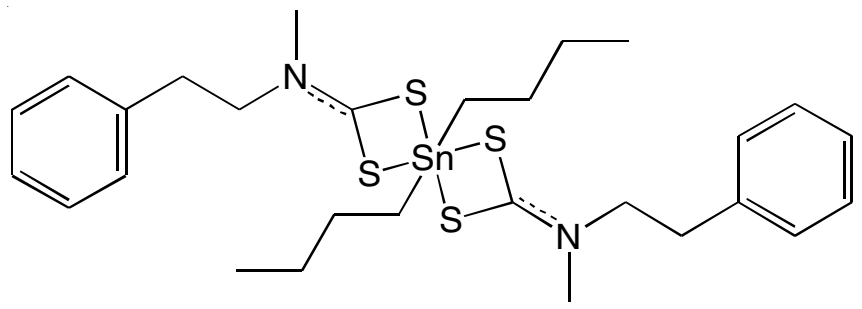

Fig. 2. Structure of dibutyltin(IV) $N$-methyl-phenethyl dithiocarbamate (2)

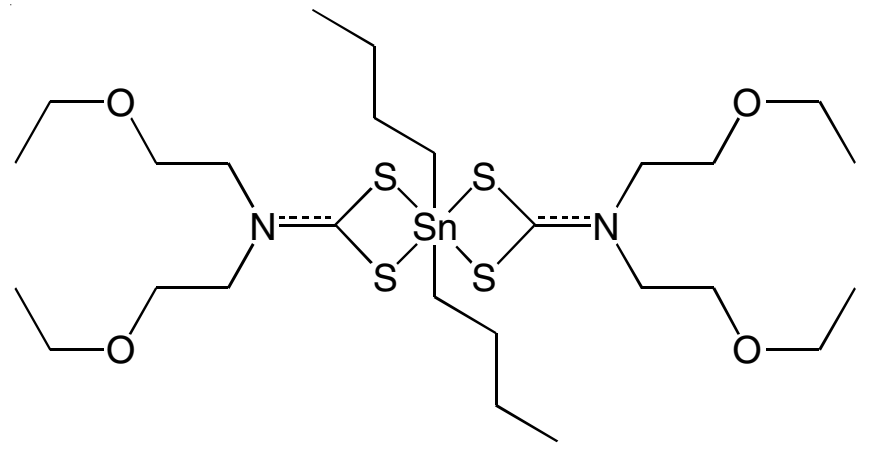

Fig. 3. Structure of dibutyltin(IV) bis(2-ethoxyethyl) dithiocarbamate (3)

CHNS elemental analysis has been done on all three complexes to determine the percentage of carbon, hydrogen, nitrogen and sulphur in the complex molecules. It was found that the observed percentages of $\mathrm{C}, \mathrm{H}, \mathrm{N}$ and $\mathrm{S}$ in all three complexes are within acceptable range compared to their theoretical values. Table- 1 summarizes the physical and elemental analysis of all three complexes.

Fourier-transform infrared spectroscopy (FTIR) spectral studies: The FTIR spectra were recorded in the range of $4000-400 \mathrm{~cm}^{-1}$. All complexes produced a strong thioureide $v(\mathrm{C}=\mathrm{N}) \mathrm{N})$ band in the range $1489-1479 \mathrm{~cm}^{-1}$ comparable to previous literature [23], which could be due to the increase of the carbon-nitrogen double bond character as the band is observed at a lower frequency in a free ligand [24]. This phenomenon occurs when electrons are delocalized towards the tin atom upon complexation [3].

The coordination nature of the ligand to the tin centre can be suggested from the number of bands observed in 1050-950 $\mathrm{cm}^{-1}$ region [23], which stands for the $v(\mathrm{C}-\mathrm{S})$ band. Single sharp bands occurring in this region signifies bidenticity whereas splitting of the same band within a difference of $20 \mathrm{~cm}^{-1}$ in the same region signifies monodenticity or anisobidenticity [24]. A sharp single peak in the range of 986 to $971 \mathrm{~cm}^{-1}$ was observed in all three complexes, suggesting the bidentate behaviour of the ligand upon the tin center [25].

The $v(\mathrm{Sn}-\mathrm{C})$ band of all three complexes occurred in the range 568.2 to $550.8 \mathrm{~cm}^{-1}$, in agreement with reported data for organotin(IV) dithiocarbamate compounds [7]. Table-2 summarizes the important FTIR absorption bands of all three complexes.

\begin{tabular}{cccc}
\multicolumn{5}{c}{ TABLE-2 } \\
\multicolumn{5}{c}{$\left.\begin{array}{c}\text { IMPORTANT FTIR ABSORPTION } \\
\text { BANDS }\left(\mathrm{cm}^{-1}\right)\end{array}\right)$ OF COMPLEXES 1-3 } \\
\hline Complex & $v\left(\mathrm{C}^{----} \mathrm{N}\right)$ & $v(\mathrm{C}-\mathrm{S})$ & $v(\mathrm{Sn}-\mathrm{C})$ \\
\hline 1 & 1488.8 & 975.4 & 550.8 \\
2 & 1487.8 & 971.2 & 553.4 \\
3 & 1479.3 & 986.2 & 568.2 \\
\hline
\end{tabular}

Nuclear magnetic resonance studies: The ${ }^{1} \mathrm{H}$ NMR chemical shifts of all three complexes were recorded in $\mathrm{CDCl}_{3}$ solution with tetramethylsilane as internal standard. The sharp singlet found at $1.59 \mathrm{ppm}$ is attributed to the proton of the methyl group attached to the tin atom in complex $\mathbf{1}$. For complexes $\mathbf{2}$ and $\mathbf{3}$, the presence of the butyl group attached to the central tin atom produced broad signals for the methylene protons in the ranges 1.42-2.10 ppm (complex 2) and 1.40$2.08 \mathrm{ppm}$ (complex 3), together with a triplet in the ranges 0.94-0.98 ppm (complex 2) and 0.92-0.96 ppm (complex 3) produced by the methyl protons. The shielding effect is caused by the attachment of the butyl group to the electropositive tin atom via carbon nuclei [26]. This effect is experienced all through the butyl carbon chain. The multiplet signals observed at 7.26-7.36 ppm (complex 1) and 7.24-7.34 ppm (complex 2) are ascribed to the protons in the phenyl groups of the ligand in both complexes. Since complexes $\mathbf{1}$ and $\mathbf{2}$ are made up of the same ligand, the protons in the ligand appear at the same chemical shifts [27]. In complex $\mathbf{3}$, a triplet can be seen at 1.18-1.22 ppm, comprising of 12 protons from the double ethoxy group on each side of the symmetrical complex. Other important ${ }^{1} \mathrm{H}$ chemical shifts of the complexes can be seen in Table-3.

TABLE-1

PHYSICAL AND ELEMENTAL ANALYSIS OF COMPLEXES 1-3

\begin{tabular}{|c|c|c|c|c|c|c|c|c|c|}
\hline \multirow{2}{*}{ Complex } & \multirow{2}{*}{ m.f. } & \multirow{2}{*}{$\begin{array}{c}\text { Yield } \\
(\%)\end{array}$} & \multirow{2}{*}{ Physical form } & \multirow{2}{*}{$\begin{array}{l}\text { m.w. } \\
(\mathrm{g} / \mathrm{mol})\end{array}$} & \multirow{2}{*}{ m.p. $\left({ }^{\circ} \mathrm{C}\right)$} & \multicolumn{4}{|c|}{ Elemental analysis (\%): Observed (Expected) } \\
\hline & & & & & & $\mathrm{C}$ & $\mathrm{H}$ & $\mathrm{N}$ & $\mathrm{S}$ \\
\hline 1 & $\mathrm{C}_{22} \mathrm{H}_{30} \mathrm{~N}_{2} \mathrm{~S}_{4} \mathrm{Sn}$ & 62 & White $\mathrm{p}$ & 569.46 & $107.3-109.2$ & $45.82(46.40)$ & $5.47(5.31)$ & $4.89(4.92)$ & $21.74(22.52)$ \\
\hline 2 & $\mathrm{C}_{28} \mathrm{H}_{42} \mathrm{~N}_{2} \mathrm{~S}_{4} \mathrm{Sn}$ & 58 & White powder & 653.62 & 103.9-106.9 & $49.74(51.45)$ & $6.78(6.48)$ & $4.75(4.29)$ & $19.69(19.62)$ \\
\hline 3 & $\mathrm{C}_{26} \mathrm{H}_{54} \mathrm{~N}_{2} \mathrm{O}_{4} \mathrm{~S}_{4} \mathrm{Sn}$ & 35 & Crystalline solids & 705.69 & $32.3-34.8$ & $45.99(44.25)$ & $7.24(7.71)$ & $3.22(3.97)$ & $18.91(18.18)$ \\
\hline
\end{tabular}


TABLE-3

${ }^{1} \mathrm{H},{ }^{13} \mathrm{C}$ AND ${ }^{119} \mathrm{Sn}$ NMR CHEMICAL SHIFTS $\delta(\mathrm{ppm})$ OF COMPLEXES 1-3

\begin{tabular}{|c|c|c|c|}
\hline \multirow{2}{*}{ NMR } & \multicolumn{3}{|c|}{ Chemical shift, $\delta(\mathrm{ppm})$} \\
\hline & Complex 1 & Complex 2 & Complex 3 \\
\hline${ }^{1} \mathrm{H}$ & $\begin{array}{l}1.59\left(\mathrm{~s}, 6 \mathrm{H}, \mathrm{Sn}-\mathrm{CH}_{3}\right) ; 3.05-3.09 \\
\left(\mathrm{t}, 4 \mathrm{H}, \mathrm{N}-\mathrm{CH}_{2}\right) ; 3.34(\mathrm{~s}, 6 \mathrm{H}, \mathrm{N}- \\
\left.\mathrm{CH}_{3}\right) ; 4.04-4.08\left(\mathrm{t}, 4 \mathrm{H}^{-} \mathrm{C}_{6} \mathbf{H}_{5}-\mathrm{CH}_{2}\right) \\
7.26-7.36\left(\mathrm{~m}, 10 \mathrm{H}, \mathrm{C}_{6} \mathbf{H}_{5}\right)\end{array}$ & 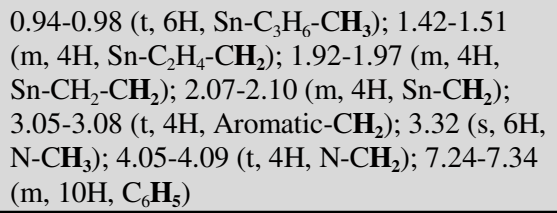 & $\begin{array}{l}0.92-0.96\left(\mathrm{t}, 6 \mathrm{H}, \mathrm{Sn}-\mathrm{C}_{3} \mathrm{H}_{6}-\mathrm{CH}_{3}\right) ; 1.18-1.22(\mathrm{t}, \\
\left.12 \mathrm{H}, \mathrm{O}-\mathrm{CH}_{2}-\mathrm{CH}_{3}\right) ; 1.40-1.49\left(\mathrm{~m}, 4 \mathrm{H}, \mathrm{Sn}-\mathrm{C}_{2} \mathrm{H}_{4^{-}}\right. \\
\left.\mathrm{CH}_{2}\right) ; 1.87-1.95\left(\mathrm{~m}, 4 \mathrm{H}, \mathrm{Sn}-\mathrm{CH}_{2}-\mathrm{CH}_{2}\right) ; 2.04-2.08 \\
\left(\mathrm{~m}, 4 \mathrm{H}, \mathrm{Sn}-\mathrm{CH}_{2}\right) ; 3.48-3.53\left(\mathrm{~m}, 8 \mathrm{H}, \mathrm{O}-\mathrm{CH}_{2}\right) ; \\
3.74-3.77\left(\mathrm{t}, 8 \mathrm{H}, \mathrm{N}-\mathrm{CH}_{2}\right) ; 4.12-4.15(\mathrm{t}, 8 \mathrm{H}, \\
\left.\mathrm{N}-\mathrm{CH}_{2}-\mathrm{CH}_{2}\right)\end{array}$ \\
\hline${ }^{13} \mathrm{C}$ & $\begin{array}{l}15.55\left(\mathrm{Sn}-\mathrm{CH}_{3}\right) ; 33.06\left(\mathbf{C}_{6} \mathrm{H}_{5^{-}}\right. \\
\left.\mathrm{CH}_{2}\right) ; 43.36\left(\mathrm{~N}-\mathrm{CH}_{3}\right) ; 58.80 \\
\left(\mathrm{~N}_{-} \mathrm{CH}_{2}\right) ; 126.74-138.02\left(\mathbf{C}_{6} \mathrm{H}_{5}\right) \\
200.02\left(\mathrm{~N}-\mathrm{CS}_{2}\right)\end{array}$ & $\begin{array}{l}13.90\left(\mathrm{Sn}-\mathrm{C}_{3} \mathrm{H}_{6}-\mathrm{CH}_{3}\right) ; 26.50\left(\mathrm{Sn}-\mathbf{C H}_{2}\right) ; 28.59 \\
\left(\mathrm{Sn}^{-} \mathrm{CH}_{2}-\mathrm{CH}_{2}\right) ; 33.05\left(\mathrm{Sn}_{2}-\mathrm{C}_{2} \mathrm{H}_{4}-\mathbf{C H}_{2}\right) ; 34.43 \\
\left(\mathbf{C}_{6} \mathrm{H}_{5}-\mathbf{C H}_{2}\right) ; 43.42\left(\mathrm{~N}^{-} \mathrm{CH}_{3}\right) ; 58.74\left(\mathrm{~N}-\mathrm{CH}_{2}\right) ; \\
126.69-138.12\left(\mathbf{C}_{6} \mathrm{H}_{5}\right) ; 200.79\left(\mathrm{~N}-\mathrm{CS}_{2}\right)\end{array}$ & $\begin{array}{l}13.82\left(\mathrm{Sn}-\mathrm{C}_{3} \mathrm{H}_{6}-\mathrm{CH}_{3}\right) ; 15.10\left(\mathrm{O}-\mathrm{CH}_{2}-\mathrm{CH}_{3}\right) ; 26.38 \\
\left(\mathrm{Sn}-\mathrm{CH}_{2}\right) ; 28.53\left(\mathrm{Sn}-\mathrm{CH}_{2}-\mathrm{CH}_{2}\right) ; 34.24\left(\mathrm{Sn}-\mathrm{C}_{2} \mathrm{H}_{4}-\right. \\
\left.\mathrm{CH}_{2}\right) ; 55.82\left(\mathrm{~N}-\mathrm{CH}_{2}\right) ; 66.64\left(\mathrm{O}-\mathrm{CH}_{2}\right) ; 67.68 \\
\left(\mathrm{~N}-\mathrm{CH}_{2}-\mathrm{CH}_{2}\right) ; 201.35\left(\mathrm{~N}-\mathrm{CS}_{2}\right)\end{array}$ \\
\hline${ }^{119} \mathrm{Sn}$ & -335.30 & -338.85 & -335.75 \\
\hline
\end{tabular}

In ${ }^{13} \mathrm{C} \mathrm{NMR}$, the presence of $\mathrm{NCS}_{2}$ peak indicates the presence of dithiocarbamate moiety [10], which is normally found in the range of $185-220 \mathrm{ppm}$ [28]. In a free dithiocarbamate ligand, $\mathrm{NCS}_{2}$ peak can be found at $205 \mathrm{ppm}$ and above [3]. Upon complexation, $\mathrm{NCS}_{2}$ carbon is more shielded, thus the ${ }^{13} \mathrm{C}$ signal is moved to a higher field compared to free ligand [29]. In case of these three complexes, a single low field resonance appeared in all complexes at 200.02-201.35 ppm, confirming the presence of the dithiocarbamate ligands. Other important ${ }^{13} \mathrm{C}$ chemical shifts of the complexes are given in Table-3.

Essentially, coordination number of the central tin atom in complexes can be identified by using ${ }^{119} \mathrm{Sn}$ NMR spectroscopy [30]. Values in the ranges of +200 to $-50 \mathrm{ppm},-90$ to $-190 \mathrm{ppm}$ and -210 to $-400 \mathrm{ppm}$ on the ${ }^{119} \mathrm{Sn}$ spectra are attributed to four-coordinate compounds, five-coordinate compounds and six-coordinate compounds, respectively [30]. As observed, all three complexes showed a peak at -335.30 ppm (complex 1), -338.85 ppm (complex 2) and -335.75 ppm (complex 3), which are all in the range of -210 to $-400 \mathrm{ppm}$. This suggests that both dithiocarbamate ligands chelate to the central tin atom in a bidentate fashion in all three complexes, in agreement with the results from the FTIR.

\section{Conclusion}

Three organotin(IV) dithiocarbamate complexes were successfully synthesized via in situ method at $<4{ }^{\circ} \mathrm{C}$. The CHNS elemental analysis, FTIR studies and ${ }^{1} \mathrm{H},{ }^{13} \mathrm{C}$ and ${ }^{119} \mathrm{Sn}$ NMR studies showed data consistent with the proposed structures of the complexes. All the characterized complexes produced the important IR bands and NMR peaks for organotin(IV) dithiocarbamate complexes, in accordance with literature.

\section{ACKNOWLEDGEMENTS}

The authors would like to thank Universiti Kebangsaan Malaysia for their financial support under the grant GGPM2016-061 and FRGS/2/2013/SKK10/UKM/02/1 in this study. We are also grateful for the technical support given by the laboratory assistants and science officers of Faculty of Science and Technology, Faculty of Health Sciences and Centre for Research \& Instrumentation Management, UKM.

\section{REFERENCES}

1. C. Pellerito, L. Nagy, L. Pellerito and A. Szorcsik, J. Organomet. Chem., 691, 1733 (2006); https://doi.org/10.1016/j.jorganchem.2005.12.025.

2. N. Awang, N.F. Kamaludin and A.R. Ghazali, Pak. J. Biol. Sci., 14, 768 (2011);

https://doi.org/10.3923/pjbs.2011.768.774.

3. J.O. Adeyemi, D.C. Onwudiwe and E.C. Hosten, J. Saudi Chem. Soc., 22, 427 (2017); https://doi.org/10.1016/j.jscs.2017.08.004.

4. S. Khan, S.A.A. Nami and K.S. Siddiqi, J. Organomet. Chem., 693, 1049 (2008);

https://doi.org/10.1016/j.jorganchem.2007.12.026.

5. M.F. Basirah, M.F. Abu Hasan, N. Mohd Sidek, W.M. Khairul and N. Ismail, J. Appl. Sci. Res., 9, 5562 (2013).

6. T.S. Basu Baul, Appl. Organomet. Chem., 22, 195 (2008); https://doi.org/10.1002/aoc.1378.

7. S. Shahzadi, K. Shahid, S. Ali, M. Mazhar and K.M. Khan, J. Iran. Chem. Soc., 2, 277 (2005);

https://doi.org/10.1007/BF03245931.

8. F. Javed, S. Ali, S. Shahzadi, N. Khalid, S. Tabassum, I. Khan, S.K. Sharma and K. Qanungo, J. Chin. Chem. Soc. (Taipei), 62, 728 (2015); https://doi.org/10.1002/jccs.201500235.

9. T.S. Basu Baul, A. Mizar, A.K. Chandra, X. Song, G. Eng, R. Jirásko, M. Holcapek, D. de Vos and A. Linden, J. Inorg. Biochem., 102, 1719 (2008); https://doi.org/10.1016/j.jinorgbio.2008.05.001.

10. N.F. Kamaludin, N. Awang, I. Baba, A. Hamid and C.K. Meng, Pak. J. Biol. Sci., 16, 12 (2013); https://doi.org/10.3923/pjbs.2013.12.21.

11. N. Khan, Y. Farina, L.K. Mun, N.F. Rajab and N. Awang, J. Mol. Struct., 1076, 403 (2014); https://doi.org/10.1016/j.molstruc.2014.08.015

12. N. Awang, Z.A. Aziz, N.F. Kamaludin and K.M. Chan, Online J. Biol. Sci., 14, 84 (2014); https://doi.org/10.3844/ojbsci.2014.84.93.

13. X. Xiao, Y. Li, Y. Dong, W. Li, K. Xu, N. Shi, X. Liu, J. Xie and P. Liu, J. Mol. Struct., 1130, 901 (2017); https://doi.org/10.1016/i.molstruc.2016.10.083.

14. N.F. Kamaludin, S.A. Zakaria, N. Awang, R. Mohamad and N.U. Pim, Orient. J. Chem., 33, 1756 (2017); https://doi.org/10.13005/ojc/330420.

15. G. Eng, X. Song, Q. Duong, D. Strickman, J. Glass and L. May, Appl. Organomet. Chem., 17, 218 (2003); https://doi.org/10.1002/aoc.423

16. E.R.T. Tiekink, Appl. Organomet. Chem., 22, 533 (2008); https://doi.org/10.1002/aoc.1441.

17. H. Nabipour, S. Ghammamy, S. Ashuri and Z.S. Aghbolagh, Org. Chem. J., 2, 75 (2010).

18. O.S. Jung and Y.S. Sohn, Bull. Korean Chem. Soc., 9, 365 (1988).

19. P.J. Heard, ed.: K.D. Karlin, Progress in Inorganic Chemistry, John Wiley \& Sons, Inc., Chap. 1 (2005).

20. B. Alama, B. Tasso, F. Novelli and F. Sparatore, Drug Discov. Today, 14, 500 (2009); https://doi.org/10.1016/j.drudis.2009.02.002. 
21. S.M. Amer, M.A. Fahmy, F.A.E. Aly and A.A. Farghaly, Mutat. Res. Genet. Toxicol. Environ. Mutagen., 513, 1 (2002); https://doi.org/10.1016/S1383-5718(01)00261-3.

22. K.J. Ivin and E.D. Lillie, Macromol. Chem. Phys., 179, 591 (1978); https://doi.org/10.1002/macp.1978.021790304.

23. F. Bonati and R. Ugo, J. Organomet. Chem., 10, 257 (1967); https://doi.org/10.1016/S0022-328X(00)93085-7.

24. D.C. Onwudiwe and P.A. Ajibade, Int. J. Mol. Sci., 12, 1964 (2011); https://doi.org/10.3390/ijms12031964.

25. J. Cookson and P.D. Beer, Dalton Trans., 15, 1459 (2007); https://doi.org/10.1039/b618088d.

26. N. Khan, Y. Farina, L.K. Mun, N.F. Rajab and N. Awang, Polyhedron, 85, 754 (2015);

https://doi.org/10.1016/j.poly.2014.08.063.
27. R. Mohamad, N. Awang and N.F. Kamaludin, Res. J. Pharm. Biol. Chem. Sci., 7, 1920 (2016).

28. H.L.M. Van Gaal, J.W. Diesveld, F.W. Pijpers and J.G.M. Van der Linden, Inorg. Chem., 18, 3251 (1979); https://doi.org/10.1021/ic50201a062.

29. N. Gupta, V. Kumar, V. Singh, A. Rajput, L.B. Prasad, M.G.B. Drew and N. Singh, J. Organomet. Chem., 787, 65 (2015); https://doi.org/10.1016/j.jorganchem.2015.03.034.

30. J. Holecek, M. Nadvornik, K. Handlir and A. Lycka, J. Organomet. Chem., 315, 299 (1986);

https://doi.org/10.1016/0022-328X(86)80450-8. 